\title{
Alfabetização científica e/ou letramento científico: reflexões sobre o Ensino de Ciências
}

\author{
Scientific literacy: reflections on Science Teaching \\ Alfabetización científica y/o literacia científica: reflexiones acerca de \\ la Enseñanza de Ciencias
}

Francisco Jucivanio Felix de Sousa ${ }^{1}$; Lígia Vieira da Silva Cavalcante²; José Claudio Del Pino ${ }^{3}$

\section{RESUMO}

O artigo apresenta os resultados de uma pesquisa qualitativa, de natureza exploratória, por meio de procedimento bibliográfico cujo objetivo foi promover a compreensão dos conceitos de Alfabetização Científica (AC) e Letramento Científico (LC) e a sua função e importância no ensino das ciências na educação básica. São apresentadas as conceituações de AC e LC, seguidas de um resgate histórico do ensino de ciências no processo de aprendizagem formal, destacando as diversas adaptações que esse ensino sofreu até sua mais recente estruturação, de acordo com os documentos que normatizam a educação brasileira. São realizadas algumas incursões visando à reflexão sobre a necessidade de uma formação integral dos educandos, com criticidade e ética, através de atividades que relacionem diferentes áreas e esferas da vida em sociedade. Conclui-se que, para atingir uma educação nesses moldes, é necessário um ensino que esteja além da assimilação de conceitos e fórmulas no âmbito do ensino das ciências, buscando o entendimento dos conceitos e aplicações no cotidiano, com vistas a uma transformação social a partir da ciência e da tecnologia.

Palavras-chave: Alfabetização Científica; Letramento Científico; Ensino; Ciências.

\begin{abstract}
The article presents the results of a qualitative research, from exploratory nature, by means of bibliographic procedure whose point is to promote the understanding of Scientific Literacy, translated to portuguese as "Alfabetização Cientifica" (AC), and Scientific Literacy, translated to portuguese as "Letramento Científico (LC) and their role and importance in science teaching in basic education. The concepts of AC and LC are presented, followed by a historical review of the science teaching in the process of formal leaning, highlighting the several adaptations this teaching has suffered until its newest structuring, according to the documents that standardize Brazilian education. Some incursions are carried out to reflect on the need of integral formation of learners, with criticality and ethics, through activities that relate different areas and spheres of life in society. It is concluded that, in order to reach such an education, it is necessary a teaching which is beyond the assimilation of concepts and formulas in the scope of science education, seeking the understanding of concepts and applications in everyday life, in order to a social transformation as of science and technology.
\end{abstract}

Keywords: Scientific Literacy; Teaching; Science.

\footnotetext{
${ }^{1}$ Doutorando do Programa de Pós-Graduação em Ensino (PPGEnsino) da Universidade do Vale do Taquari (UNIVATES) e Professor do Instituto Federal de Educação, Ciência e Tecnologia do Ceará (IFCE), Maracanaú/CE - Brasil. E-mail: jucivaniofelix@gmail.com

2 Mestra em Ensino e Professora e Coordenadora do Curso de Bacharelado em Serviço Social da Faculdade Princesa do Oeste (FPO), Crateús/CE - Brasil. E-mail: ligia.vieira@fpo.edu.br

3 Professor do Programa de Pós-Graduação Educação em Ciências da Universidade Federal do Rio Grande do Sul (UFRGS), e dos Programas de Pós-Graduação Ensino e Ensino de Ciências Exatas ambos da Universidade do Vale do Taquari (UNIVATES), RS - Brasil. E-mail: delpinojc@yahoo.com.br
} 


\section{RESUMEN}

El artículo presenta los resultados de una investigación cualitativa de naturaleza exploratoria, por medio del procedimiento bibliográfico, que tiene por objetivo fomentar la comprensión de los conceptos de la Alfabetización Científica (AC) y de la Literacia Científico (LC) y su finalidad e importancia en la enseñanza de las ciencias en la educación básica. Son presentadas las conceptuaciones de $A C$ y de $L C$, enseguida de un rescate histórico de la enseñanza de ciencias en el proceso de aprendizaje formal, destacando las diversas adaptaciones que esa enseñanza sufrió hasta su más reciente estructuración, en conformidad con los documentos que normatizan la educación brasileña. Algunas incursiones se realizan con vistas a la reflexión sobre la necesidad de una formación integral de los educandos, con criticidad y ética, por medio de actividades que relacionen áreas y esferas de la vida social. Se concluye que, para alcanzar una educación en esa manera, es necesaria una enseñanza que vaya más allá de la asimilación de conceptos y fórmulas en el ámbito de la educación científica, buscando comprender los conceptos y aplicaciones en el cotidiano, con la finalidad de una transformación social, partiendo de la ciencia y de la tecnología.

Palabras clave: Alfabetización científica; Literacia científica; Enseñando; Ciencias.

\section{INTRODUÇÃO}

É com o advento da Constituição Federal de 1988 que a educação se constitui como um direito de todos, visando ao pleno desenvolvimento do ser social, sua preparação para o exercício da cidadania e à qualificação para o mercado de trabalho. A promoção de uma educação nesses moldes é dever do Estado e da família, promovida e incentivada com a colaboração da sociedade (BRASIL, 1988).

As atuais políticas educacionais para a Educação Básica no país, onde destacam-se a Lei de Diretrizes e Bases da Educação Nacional (LDB) (BRASIL, 1996) e a Base Nacional Comum Curricular (BNCC) (BRASIL, 2017), normatizam e orientam quanto ao desenvolvimento do educando, lhe assegurando uma formação crítica e emancipadora, que não apenas o capacite para o exercício de uma determinada profissão futura, mas que o prepare para o pleno exercício da cidadania.

Assim, o ensino de ciências na educação básica necessita estar envolvido com distintas situações vivenciadas pelo sujeito em sua vida cotidiana. Se vislumbrarmos um ensino que se proponha a uma prática emancipatória desse ser, precisaremos conjeturar ações que promovam sua participação efetiva na sociedade, em que possa resolver problemas do cotidiano e interagir com os seus pares de forma crítica e reflexiva, a partir de capacidades e competências adquiridas durante o processo educativo.

Quando a pauta é, pois, preparar os estudantes para a vida em sociedade, de forma crítica e responsável, através de uma educação científica, teremos uma pluralidade semântica para designar tais propostas, como: Alfabetização Científica, Letramento Científico e, ainda, Enculturação Científica.

Para Chassot (2003, p. 91), a Alfabetização Científica (AC) é considerada como uma das dimensões que potencializam alternativas que privilegiam uma educação mais comprometida, que vai possibilitar o entendimento da ciência. O autor diz que a ciência é uma linguagem, portanto, "[...] ser alfabetizado cientificamente é saber ler a linguagem em que está escrita a natureza".

Ainda, segundo o autor, há uma outra dimensão, que é de propiciar a todos os sujeitos uma alfabetização científica na perspectiva de inclusão social. "Há uma continuada necessidade de fazermos com que a ciência possa ser não apenas medianamente entendida por todos, mas, e 
principalmente, facilitadora do estar fazendo parte do mundo" (CHASSOT, 2003, p. 93).

Para Diesel et al. (2016, p. 62), o Letramento Científico (LC) ultrapassa a simples conquista das competências na decifração dos sinais da escrita. "Vai desde compreender os princípios básicos de fenômenos do cotidiano até a capacidade de tomada de decisão em questões específicas da ciência e tecnologia em que estejam diretamente envolvidos, sejam decisões pessoais ou de interesse público".

Seja utilizando o termo Alfabetização Científica ou Letramento Científico, as explanações dos autores nos indicam um ponto convergente, que é da construção crítica, ética e comprometida das ações dos sujeitos, dos quais aqui destacamos os alunos, em relação à ciência e à tecnologia, na transformação do mundo em que vivem.

A BNCC também demonstra sua preocupação com essa formação, indicando que, no desenvolvimento das atividades de sala de aula, deve-se promover, por meio da AC, "a capacidade (do aluno) de compreender e interpretar o mundo (natural, social e tecnológico), mas também de transformá-lo com base nos aportes teóricos e processuais das ciências" (BRASIL, 2017, p.321).

Essa compreensão pretendida pela BNCC está ligada aos objetivos de formar um cidadão reflexivo, que inclua o poder decisório no enfrentamento das diversas situações a serem vividas em seu meio social, e não somente naquelas simuladas em seu contexto escolar, mas em situações além dos muros da escola.

O ensino de ciências precisa contemplar os espaços formais e não formais explorados, vivenciados pelo sujeito, "[...] pois não é somente nos espaços escolares que acontece a aprendizagem e o ensino, mas também nos mais diferentes espaços não formais ou informais" (SCHVINGEL et al., 2016, p.186).

A concepção de educação científica deve estar atrelada às modificações do ensino que acontecem nos espaços formais, devendo ocorrer uma interação entre eles e os meios que os cercam, observando-se as aprendizagens de ensino não formais e propondo-se um diálogo constante para a formação crítica dos sujeitos envolvidos.

Andrade (2018) argumenta que, embora saibamos da necessidade de termos uma prática escolar que considera o contexto histórico-social em que o aluno está inserido, nos ambientes formais de ensino o que se observa é que o processo de ensino das ciências ainda é mediado, muitas vezes, tão somente pela memorização de informações, limitando-se a conteúdos curriculares que não fazem conexão entre si e sem nenhuma relação com o cotidiano dos estudantes presentes nas salas de aula de nossas escolas.

Dessa forma, concordamos com Teixeira (2013) quando afirma que pensar sobre o que significa a alfabetização científica é, na verdade, refletir sobre as funções da educação científica, qual o seu papel, onde ela acontece e de que formas. Por isso, é necessário dialogarmos acerca das concepções e das diversas possibilidades sobre o que é educação científica, o que se pretende com tal educação e de que forma podemos alcançá-la.

Contudo, muitos professores desconhecem os conceitos e os objetivos da Alfabetização Científica/Letramento Científico, dificultando a implementação de atividades escolares que contribuam e caminhem na direção dessa educação emancipadora. Tal assertiva pôde ser confirmada pelos autores deste artigo ao cursarem a disciplina de Fundamentos de Alfabetização Científica e Tecnológica ofertada pelo Programa de Pós-Graduação em Ensino da Universidade do Vale do Taquari - Univates, em que muitos alunos do programa, professores provenientes de cursos de licenciatura e 
bacharelado, não recordavam de terem tido contato com tais conteúdos durante sua formação (graduação e pós-graduação).

Assim, o presente artigo teve como objetivo promover a compreensão sobre os conceitos da Alfabetização Científica (AC) e Letramento Científico (LC), corroborando para a reflexão sobre a sua função e importância na aprendizagem escolar. Almeja-se, pois, a partir dessa compreensão, que se vislumbrem algumas possibilidades para que a escola e os processos educacionais estejam conectados às diversas realidades da sociedade que a cercam, com vistas a uma transformação social a partir da ciência e da tecnologia.

O artigo está organizado da seguinte forma: de início, apresentamos a metodologia adotada para realização deste trabalho; em seguida, abordamos os desafios na conceituação da AC e LC; posteriormente, discorremos sobre o ensino de ciências no contexto da aprendizagem formal, trazendo um resgate histórico e algumas reflexões. Por fim, seguem as considerações finais e as referências.

\section{METODOLOGIA}

Para elaboração deste artigo foi realizada uma pesquisa de abordagem qualitativa. Este tipo de abordagem responde a questões muito particulares e trabalha com um nível de realidade social que não deve e não pode ser quantificado (MINAYO, 2015).

Segundo Moraes e Galiazzi (2013), as pesquisas qualitativas têm como objetivo o aprofundamento da compreensão do fenômeno investigado, por meio de uma análise rigorosa e criteriosa. Sua intenção é interpretar, compreender e reconstruir conhecimentos existentes em relação à temática investigada.

Essa abordagem foi apropriada para o objetivo desta pesquisa, uma vez que possibilitou a compreensão sobre os conceitos de AC e LC e a sua importância no ensino das ciências, com vistas à formação de um aluno cidadão, crítico, ético e comprometido com a realidade e a transformação social.

Assim, a presente pesquisa, no tocante aos seus objetivos, pode ser classificada como exploratória. De acordo com Gil (2018, p. 25):

As pesquisas exploratórias têm como propósito proporcionar maior familiaridade com o problema, com vistas a torná-lo mais explícito ou a construir hipóteses. Seu planejamento tende a ser bastante flexível, pois interessa considerar os mais variados aspectos relativos ao fato ou fenômeno estudado. A coleta de dados pode ocorrer de diversas maneiras, mas geralmente envolve: 1 . levantamento bibliográfico; 2. entrevistas com pessoas que tiveram experiência prática com o assunto; e 3. análise de exemplos que estimulem a compreensão (SELLTIZ et al. apud GIL, p. 25).

Para alcançar as proposições deste trabalho, foi realizada uma pesquisa do tipo bibliográfica. Segundo Gil (2008), este tipo de pesquisa busca conhecer diversas contribuições científicas quanto ao fenômeno sobre o qual se deseja refletir. Assim, buscou-se levantar e discorrer, a partir de pesquisas em livros, periódicos e legislações, sobre as seguintes categorias de análise: Alfabetização Científica (AC), Letramento Científico (LC) e Ensino de Ciências. 
As produções acadêmicas relacionadas à proposta desta pesquisa foram consultadas na plataforma do Google Scholar, em julho de 2021, com recorte temporal dos últimos dez anos e classificação por relevância. A busca foi dividida em duas etapas. A primeira utilizando os descritores "alfabetização científica" e "letramento científico" e a segunda com os descritores "alfabetização científica", "ensino de ciências" e "BNCC". Foram elencados, dentre os dez artigos mais relevantes listados para cada busca, aqueles que mais se aproximavam do objetivo deste estudo.

A partir do levantamento, leitura e análise dos textos e legislações foi possível elaborar este trabalho, de caráter explicativo, sobre a concepção de alfabetização e letramento científico e sua relevância no ensino das ciências na educação básica, visando um ensino para além da memorização de conceitos e fórmulas, mas que busca o entendimento dos conteúdos e sua aplicação nos diversos contextos educacionais e na sociedade de forma geral.

\section{ALFABETIZAÇÃO CIENTÍFICA (AC) E/OU LETRAMENTO CIENTÍFICO (LC): DESAFIOS CONCEITUAIS}

Baseados no que apontam Sasseron e Carvalho (2008, p. 334), que "[...] a ideia de Alfabetização Científica ainda se mostra controversa em torno de sua definição [...]", necessitamos compreender os conceitos para que possamos realmente construir um processo de ensino para a pesquisa e reflexões além dos conteúdos a serem ensinados na escola.

Teixeira (2013) compreende que os conceitos de alfabetização e letramento são estudados por diversos pesquisadores que atuam até mesmo em campos diferentes, como a linguagem ou o ensino. A autora reitera que existem diversas pesquisas que buscam refletir acerca da pertinência do uso dos termos "alfabetização" e "letramento" para a utilização no ensino de ciências no nosso país, e, por se tratar de um termo polissêmico, não há consenso sobre o seu significado na comunidade científica. Porém, alerta que é necessário ampliar a compreensão do tema, analisando os diversos sentidos atribuídos à expressão scientific literacy.

Sasseron e Carvalho (2011) corroboram que, relacionado à tradução dos termos, a expressão inglesa vem sendo traduzida como "letramento científico", enquanto as expressões francesa e espanhola, literalmente falando, significam "alfabetização científica". Elas descrevem que o pesquisador Paul Hurd foi o primeiro que empregou o termo "scientific literacy", expressão utilizada no livro "Science Literacy: Its Meaning for American Schools", publicado em 1958.

As autoras procuram enfatizar os diversos contextos aos quais esse termo pode nos remeter, porém, enfatizam que é necessário compreender e refletir acerca das múltiplas relações entre as ciências e a sociedade que nos cerca, ao afirmarem que:

Nesse sentido, as ideias convergem para a cultura científica e suas especificidades. E assim como em qualquer outra cultura, entender quais suas regras e características para poder se comunicar com seus membros, exige que se tenha consciência de seus temas de interesse, de como tais temas foram trabalhados dentro da cultura, das relações existentes entre diferentes conhecimentos de seu escopo, além de perceber e reconhecer a estrutura por meio da qual se produz tais conhecimentos e que permite o reconhecimento dos mesmos como próprios desta cultura (SASSERON; CARVALHO, 2011, p. 63). 
Percebemos que as autoras nos alertam para que possamos refletir acerca dos aspectos a que a cultura científica nos remete e das diversas relações e temas existentes, para que possamos explorálos nos nossos espaços de ensino e de aprendizagem.

Já, relacionado ao termo "letramento", as pesquisadoras Soares (2004) e Kleiman (2005) abordam que a palavra remete a um vasto conhecimento, capacidades, habilidades, valores e funções sociais. Os significados atribuídos ao termo extrapolam a escola e o processo de alfabetização, englobado, assim, os processos e os contextos da sociedade, e compreendem que o letramento envolve múltiplas capacidades e conhecimentos.

Apoiando-se nas ideias de Paulo Freire, Sasseron e Carvalho (2011) optaram pela apropriação da expressão "alfabetização científica", por levar o termo "alfabetização" de forma literal. Dessa maneira, compreendem que estar alfabetizado é mais do que ter o domínio psicológico e mecânico das técnicas de leitura e escrita. $O$ processo de alfabetização precisa desenvolver em uma pessoa qualquer a capacidade de organizar o seu pensamento de maneira lógica e ajudá-la a possuir uma consciência crítica em relação ao mundo que a cerca.

Corroboram com este entendimento Santos e Mortimer (2002), ao indicarem que o desenvolvimento da alfabetização científica e tecnológica dos sujeitos, por meio de uma educação que privilegia o enfoque ciência-tecnologia-sociedade (CTS), auxiliará o aluno na construção de conhecimentos, de habilidades e de valores necessários para subsidiar tomadas de decisões responsáveis sobre questões que envolvem CTS na sociedade e sua ação sobre elas.

Entendemos que, embora tenhamos nomenclaturas diferentes, entre os investigadores da área, os mesmos possuem em comum a busca pela formação de cidadãos reflexivos, e procuram estimular um ensino de ciências que interaja com as problemáticas da sociedade, procurando constituir a AC e/ou o LC como uma busca de melhorias da relação do sujeito com o mundo coletivo em que ele vive. Portanto, o sentido indicado para o ensino é o mesmo, ainda que as expressões utilizadas sejam diferentes.

Os conceitos de AC e o LC apresentam importantes contribuições para que tenhamos reflexões no processo de melhorias no campo científico e tecnológico, além de contribuírem para mudanças no ensino de ciências no ensino básico.

[...] é possível destacar objetivos que envolvem AC e LC: democratizar o acesso ao conhecimento científico e tecnológico; formar cidadãos para compreender, atuar e transformar sua realidade; valorizar a Ciência enquanto fator de inclusão social; reconhecer que a Ciência pode trazer benefícios ou malefícios - a depender do uso de que faz dela. Assim, independente do conceito adotado, o que se evidencia é a formação do cidadão, vinculando a luta pela igualdade social e pelo fortalecimento de pesquisas, inovações e desenvolvimento (BRANCO et al., 2018, p. 705).

Conforme apontam Branco et al. (2018), é necessário assimilarmos os objetivos da AC e LC para que o processo de ensino de ciências seja compreendido nos espaços educativos como algo problematizador e que possibilite que os educandos consigam compreender o mundo de forma sistêmica e sejam capazes de criar e implementar ações efetivas para os diversos dilemas enfrentados pela sociedade. 


\section{O ENSINO DE CIÊNCIAS NO PROCESSO DE APRENDIZAGEM FORMAL: REGASTE HISTÓRICO E REFLEXÕES}

Os trabalhos recentes das pesquisadoras Oliveira (2017) e Andrade (2018) apontam que o ensino de ciências em nosso país sofreu diversas adaptações ao longo dos tempos até chegar o mais recente documento normativo da educação brasileira, aprovado pelo Conselho Nacional de Educação (CNE) em dezembro de 2017, a Base Nacional Comum Curricular (BNCC).

Até os anos de 1960, o cenário escolar era dominado pelo ensino tradicional, o qual se baseava na transmissão e recepção de conteúdo. Naquele período, exigia-se pouco a participação dos alunos e o ensino de ciências era meramente teórico, baseado em decorar teorias e fórmulas, muitas vezes sem apresentar nenhuma aplicação aos conteúdos estudados. Verifica-se, dessa forma, que as práticas escolares eram fortemente centradas no docente.

Andrade (2018) reforça que, a partir das décadas de 1950 e 1960, ocorreu a necessidade de formulação de propostas curriculares nas disciplinas de física, química e biologia, pois o mundo passou por novas descobertas durante a Segunda Guerra, e esses conteúdos permaneciam fora das escolas, ou seja, da realidade dos alunos.

A partir da Lei de Diretrizes e Bases da Educação Nacional (LDB), de n. ${ }^{0} 4.024 / 61$, vislumbrou-se a valorização de uma metodologia mais participativa. Relativo ao ensino de ciências, antes era estudado somente nos dois últimos anos do ginasial (equivalente hoje ao $8^{\circ}$ e $9^{\circ}$ anos do ensino fundamental II). Após a promulgação da lei, passou a ser obrigatório desde os primeiros anos do ginasial atualmente do $6^{\circ}$ aos $9^{\circ}$ anos.

Já, no ano de 1971, com a LDB n. ${ }^{0}$ 5.692/71, o ensino de ciências se tornou obrigatório para os primeiros oito anos do ensino fundamental e, consoante Oliveira (2017), "[...] o ensino de Ciências passou a ter a função de desenvolver junto aos discentes sua criticidade por meio de métodos científicos (p. 17)". Porém, cabe nos questionarmos: na prática docente, nas atividades exigidas para os estudantes, ocorreram essas modificações objetivadas para o ensino? Conforme relatos da autora, o ensino continuava atrelado simplesmente à transmissão de conteúdos e os contextos a serem explorados e refletidos ainda não tinham voz na perspectiva de ensino formal.

Nos períodos subsequentes às décadas de 80 e 90, os diversos problemas sociais e econômicos no nosso país continuaram a afetar a educação. Porém, aumentou-se a busca por melhorias no ensino e o início de problematizações relacionadas ao movimento Ciência, Tecnologia e Sociedade (CTS) ${ }^{4}$, que buscava um ensino de ciências transformador e participativo.

Andrade (2018, p. 31) relata que os docentes da área de ciências da época "[...] se preocupavam com as novas tecnologias que permeiam o sistema de ensino, havendo a preocupação com a introdução de jogos e do uso de computadores em suas práticas". Essas ações visavam promover o processo decisório e tecnologias que priorizam a tomada de decisões, perspectivas que estão atreladas ao processo de AC.

\footnotetext{
${ }^{4}$ Os pesquisadores Santos e Mortimer (2002) procuram utilizar o conceito de bybee para caracterizar a orientação curricular de CTS como pesquisa e desenvolvimento de currículos que contemplem, entre outros: (i) a apresentação de conhecimentos e habilidades científicos e tecnológicos em um contexto pessoal e social; (ii) a inclusão de conhecimentos e habilidades tecnológicos; (iii) a ampliação dos processos de investigação de modo a incluir a tomada de decisão; e (iv) a implementação de projetos de CTS no sistema escolar.
} 
Em 1996 foi promulgada a atual LDB, lei n. ${ }^{0}$ 9.394/1996, que em seu artigo 22 compreende que a "[...] educação básica tem por finalidades desenvolver o educando, assegurar-Ihe a formação comum indispensável para o exercício da cidadania e fornecer-lhe meios para progredir no trabalho e em estudos posteriores" (BRASIL, 1996). Esse objetivo está atrelado ao saber científico que visa contribuir com a formação crítica de cidadãos.

No ano de 1997, o Ministério da Educação (MEC) organiza um novo modelo curricular por meio dos Parâmetros Curriculares Nacionais para o ensino fundamental (PCNs), recomendados para todos os sistemas de ensino, sendo inserido o uso da transversalidade nas disciplinas curriculares do ensino fundamental.

Os temas transversais envolvem os conteúdos de caráter social que devem ser incluídos nos currículos de forma "transversal", ou seja, não como uma área específica, e sim como um conteúdo que deve ser contemplado junto com as diversas áreas de conhecimento. Dentre os temas transversais que podem ser abordados, destacamos, por exemplo, saúde, meio ambiente, sexualidade, ética, pluralidade e cultura.

Em 2017, tivemos a aprovação da Base Nacional Comum Curricular, um documento norteador e referencial para a elaboração dos currículos das escolas, baseados em competências e habilidades. Apresentadas no documento como os conhecimentos, as habilidades, as atitudes e os valores para atuação na vida cotidiana, exercício da cidadania e inserção no mundo do trabalho. Na BNCC temos uma articulação e detalhamento dos níveis de ensino e apresentação das etapas para a educação básica.

Dentre os objetivos propostos para a área de Ciências da Natureza encontramos o compromisso com o desenvolvimento do letramento científico, que envolve a capacidade de compreender e interpretar o mundo (natural, social e tecnológico). Tal proposta necessita perpassar por práticas pedagógicas que possam envolver a elaboração de um ensino que envolva pesquisas, estratégias pedagógicas que estimulem a percepção, compreensão da definição e do processo de AC e LC, as experiências e os processos de interação e investigação vivenciados nos diversos espaços de aprendizagem.

Nessa perspectiva, Couto e Nascimento (2020) afirmam que o ensino de ciências se torne investigativo, visando oportunizar aos alunos olharem as situações problemas e elaborarem possíveis soluções, incentivando o uso de uma linguagem cultural e científica, além de testar hipóteses e possibilidades, gerando questionamentos e argumentos, exercendo o poder de criticidade almejado para a AC e/ou LC que deve ser aprendido e vivenciado no processo escolar.

Refletindo sobre o que referencia a BNCC e sua relação com os conceitos de AC e LC, trazemos à baila o que expressa Sasseron (2018), nos aspectos relacionados ao ensino de ciências. A autora salienta que o letramento científico é destacado como compromisso da área para o ensino fundamental. Relaciona ainda que o ensino das ciências deva ocorrer na articulação com outros campos de saber, integrando os processos, práticas e procedimentos da investigação científica.

Sasseron (2018, p. 1070) faz uma ressalva à construção dos procedimentos da investigação científica proposta pela BNCC: "[...] a definição de processo investigativo faz menção ao desenvolvimento contínuo e que este seria o fundamento para o surgimento de reflexões". A autora alerta que a visão crítica e reflexiva não surge de forma espontânea, as reflexões são elementos fundantes do processo de ensino e aprendizagem. 
Os estudos de Cavalcante Júnior et al. (2021) referem que, por mais que nas legislações e nos projetos pedagógicos conste essa menção à formação crítica e cidadã, nem sempre ela é materializada em sala de aula. A educação bancária, da qual muitos professores foram, um dia, os sujeitos passivos, acaba sendo reproduzida por eles com seus alunos.

O professor continua tendo centralidade no processo de ensino, e suas aulas, muitas vezes, baseiam-se em cópias, memorizações e exercícios com conteúdo que apresentam pouca ou nenhuma significância para o aluno, com currículo e disciplinas "engessadas" que não dialogam entre si, criando barreiras para a aprendizagem numa perspectiva de cidadania plena (CAVALCANTE JÚNIOR et al., 2021, p. 15).

Continuam referindo que os docentes precisam ter ciência do seu importante papel na mediação de processos de ensino e aprendizagem com vistas a uma educação libertadora, de conhecimento da sociedade, de capacitação dos sujeitos na transformação da realidade.

Semelhante são as contribuições de Cortez e Del Pino (2018; 2019), ao referirem em seus estudos que a abordagem CTS é uma excelente prática na melhoria do ensino das ciências. Numa análise sobre as Diretrizes Curriculares Nacionais para a formação de professores na área de ciências, verificaram que existe uma preocupação expressa nesses documentos no tocante ao desenvolvimento de um ensino contextualizado, não fragmentado e capaz de despertar nos acadêmicos uma personalidade crítica e cidadã.

Contudo, em entrevistas com coordenadores de cursos de licenciatura para as áreas de química, física e ciências biológicas, os mesmos refeririam que os cursos carregam fortes traços de cientificismo, com características de uma educação bancária e fragmentada. Informaram ainda que predomina, em diversas disciplinas, o ensino do conhecimento científico neutro e inquestionável, sem privilegiar a promoção de uma formação cidadã desses futuros professores (CORTEZ e DEL PINO, 2019).

Chassot (2003) nos alerta que apenas conseguiremos fazer alfabetização científica quando o ensino da ciência - em todos os níveis, incluindo aí também a graduação e a pós-gradução -, contribuir para a compreensão de conhecimentos que permitam aos alunos a tomada de decisões. Ademais, deverá também propiciar que se percebam tanto as utilidades da ciência e suas aplicações para melhoramento da qualidade de vida, quanto as limitações e consequências negativas do seu desenvolvimento.

Precisamos ainda reforçar a necessidade de investimentos em políticas públicas educacionais que possam valorizar e incentivar os aspectos relacionados ao ensino de AC e LC. Autores como Reis, Cavalcante e Oliveira (2020, p. 11) reforçam essa preocupação ao destacarem o quão importante é o incentivo para a pesquisa na área do ensino, ciências e tecnologia na educação básica. Para que possamos ter um ensino voltado para a transformação da educação e a implementação da AC, é necessária "[...] uma revolução em todo o sistema de ensino nacional, capaz de garantir o acesso e principalmente a permanência dos alunos na escola".

Com base nesse breve relato histórico da trajetória acerca do ensino de ciências nos documentos oficiais, percebemos uma considerável evolução no que se refere ao ensino da disciplina e os diversos aspectos abordados por eles. Concordamos com Sasseron (2018), ao afirmar que é necessário desenvolver práticas científicas e ações investigativas como forma de garantir que o ensino de ciências da natureza aborde mais do que apenas fatos das ciências, contribuindo para a ampliação do conhecimento dos estudantes sobre a área e sobre o mundo que os cerca. 
Os estudos de Santos e Mortimer (2002) nos indicam que por meio de uma educação de CTS é possível desenvolver a alfabetização científica dos alunos. Essa proposta educacional tem três objetivos gerais: o primeiro, aquisição de conhecimentos; o segundo, utilização de habilidades; e, por fim, o desenvolvimento de valores. Destaca como conhecimentos e habilidades a serem desenvolvidos:

[...] a auto-estima, a comunicação escrita e oral, o pensamento lógico e racional para solucionar problemas, a tomada de decisão, o aprendizado colaborativo/cooperativo, a responsabilidade social, o exercício da cidadania, a flexibilidade cognitiva e 0 interesse em atuar em questões sociais (SANTOS, MORTIMER, 2002, p. 114).

Portanto, o ensino de ciências precisa contemplar atividades que relacionem diferentes áreas e esferas da vida em sociedade, como as ciências e seus produtos estão presentes e permeiam o nosso cotidiano e, por isso, são estreitamente relacionados à nossa vida.

Tais atividades e proposições devem focar na formação de valores e atitudes em contraposição às memorizações e preparações para provas e vestibulares. Devem contemplar uma abordagem temática em oposição aos programas alheios ao cotidiano dos educandos. Atividades que instiguem e motivem a participação dos alunos em contraposição a um ensino passivo, que lhes permitam expressar suas ideias, aspirações e soluções. Para Santos e Mortimer (2002, p. 127):

Não adianta apenas inserir temas sociais no currículo, sem qualquer mudança significativa na prática e nas concepções pedagógicas. Não basta as editoras de livros didáticos incluírem em seus livros temas sociais, ou disseminarem os chamados paradidáticos. Sem uma compreensão do papel social do ensino de ciências, podemos incorrer no erro da simples maquiagem dos currículos atuais com pitadas de aplicação das ciências à sociedade.

Sasseron e Carvalho (2011), ao estudarem, à luz de diversos autores, sobre as habilidades que a alfabetização científica deve promover, as elencaram em três grandes eixos, capazes de fornecer bases necessárias quando da elaboração e planejamento de aulas que visam à AC. Tais eixos foram nomeados de "Eixos Estruturantes da Alfabetização Científica".

O primeiro refere-se à compreensão básica de termos, conhecimentos e conceitos científicos fundamentais. Assim, abre-se a possibilidade de trabalhar com os educandos a construção de conhecimentos científicos e a sua aplicação apropriada em situações diversas do cotidiano. O segundo eixo ocupa-se da "[...] compreensão da natureza das ciências e dos fatores éticos e políticos que circundam sua prática (p. 75)". Vem fornecer subsídios para que o caráter humano e social inerente às investigações científicas seja colocado em pauta, contribuindo para reflexões e análises com vistas à tomada de decisões. O último eixo compreende o entendimento das relações entre ciência, tecnologia, sociedade e meio ambiente. Trata, pois, da identificação de como essas esferas se entrelaçam e como uma correta aplicação dos saberes construídos pelas ciências corrobora na construção de um futuro mais sustentável para a sociedade e para o planeta. As autoras concluem afirmando que:

[...] as propostas didáticas que surgirem respeitando esses três eixos devem ser capazes de promover o início da Alfabetização Científica, pois terão criado oportunidades para trabalhar problemas envolvendo a sociedade e o ambiente, discutindo, concomitantemente, os fenômenos do mundo natural associados, a construção do entendimento sobre esses fenômenos e os empreendimentos gerados a partir de tal conhecimento (SASSERON; CARVALHO, 2011, p. 76). 
Sustentamos, a partir dos estudos aqui elencados, que, para concretizar o ensino de ciências nos moldes propostos pela $\mathrm{AC}$, precisamos ir além do que nos exigem e propõem os documentos oficiais. A educação científica deve perpassar a formação dos professores que formam professores, para que, desde o ensino superior, se vivenciem essas discussões, com proposições e ações que contribuam, posteriormente, com o ensino das ciências na educação básica, contemplando uma formação integral dos educandos, com entendimento, criticidade e ética, visando à transformação (em algo melhor) do mundo em que vivemos.

\section{5. À GUISA DE CONCLUSÃO}

Ao buscarmos discutir a importância do ensino científico na formação de cidadãos, tivemos a pretensão de refletir e compreender os conceitos da alfabetização científica e letramento científico, e dialogarmos sobre o papel de um ensino que fosse além da assimilação de conceitos e fórmulas no âmbito do ensino das ciências. Buscamos apresentar o percurso histórico desse ensino na educação formal nas escolas brasileiras e compreender que precisamos estar em constante diálogo com a prática de atividades que incentivem a participação dos discentes. Dessa forma, é fundamental que se exija a reflexão em torno das atividades, indo além do ato de decorar fórmulas, buscando o entendimento dos conceitos e aplicações no cotidiano.

Ao compreendermos as concepções sobre AC e LC, enxergamos que ambas caminham no intuito e com ações para possibilitar aos estudantes o desenvolvimento e o uso de raciocínio científico de forma crítica, e com condições que possam compreender e desenvolver estratégias para modificar e aperfeiçoar o mundo que os cerca. O conhecimento científico está envolto nessa compreensão de mundo, com a discussão de possibilidades de se viver nele. Um sujeito alfabetizado cientificamente deve ter o entendimento de ser capaz de enfrentar e solucionar problemas encontrados no seu cotidiano.

Compreendemos que o ensino de ciências é desafiador aos educadores e aos educandos. Nem sempre conseguiremos superar os desafios e tensionamentos presentes nas escolas, que vão desde a falta de estruturas físicas, de material didático, de formação profissional adequada, com reduzido número de profissionais, além das diversas expressões da questão social vivenciadas pelos nossos discentes, como fome, violências, questões de renda e empregabilidade dos pais, dentre outras. Contudo, se o professor compreender a educação à luz das legislações vigentes e se propor a utilizar um ensino com o propósito de educar cientificamente, poderá tornar o processo de ensino e aprendizagem de ciências com significado para os estudantes, com o sentido de apropriação de conceitos, para além de simples memorização dos conteúdos propostos, buscando os conhecimentos úteis à vida e propiciando uma transformação social.

No processo de tomada de decisões se exige que tenhamos diversas informações e capacidade de análise para as múltiplas situações que nos envolvem. Dessa forma, cabe-nos questionar: Será que as propostas de ensino presentes em nossas escolas estão proporcionando esses conhecimentos para que se possa pensar de forma sistêmica? As situações-problema apresentadas nas instituições estão refletindo essa necessidade de pensamento holístico? São reflexões que precisamos nos instigar para que possamos estar sempre atentos ao que estamos nos propondo nas redes de ensino.

Entendemos que conhecer as múltiplas possibilidades advindas pela AC e LC, por meio de um trabalho coletivo da prática docente e das modificações no processo de ensino, permitirá um processo de 
melhoria na aprendizagem dos discentes e a busca pelo conhecimento de forma ativa no contexto social em que vivem. Ademais, ajudar-lhes-á na constituição e no surgimento de diversos questionamentos, proporcionando uma transformação do conhecimento e não apenas repetições de práticas científicas ensinadas no ambiente escolar.

Esperamos que as explanações e reflexões suscitadas neste estudo propiciem uma (re)significação da prática docente, em que se busque o ensino das ciências não apenas como mera reprodução de conteúdos, mas que os processos de ensino e aprendizagem proporcionem a formação de sujeitos críticos, reflexivos e transformadores.

\section{AGRADECIMENTOS}

O presente trabalho foi realizado com apoio da Coordenação de Aperfeiçoamento de Pessoal de Nível Superior - Brasil (CAPES) - Código de financiamento 001, programa de Pós-Graduação em Ensino PPGEnsino da Universidade do Vale do Taquari - Univates.

\section{REFERÊNCIAS}

ANDRADE, M. J. Alfabetização científica no ensino médio: concepções como indicadores de práticas docentes em biologia. 2018. 175 f. Dissertação (Mestrado) - Curso de Programa de Pós-Graduação em Educação Maria José, Centro de Educação, Universidade Federal da Paraíba, João Pessoa, 2018.

BRANCO, A. B. G. et al. Alfabetização e letramento científico na BNCC e os desafios para uma educação científica e tecnológica. Revista Valore, [S.I.], v. 3, p. 702-713, dez. 2018.

DOI:10.22408/reva302018174702-713.

BRASIL. Base Nacional Comum Curricular (BNCC). 2017. Educação é a Base. [online] Disponível em:

http://basenacionalcomum.mec.gov.br/images/BNCC_EI_EF_110518_versaofinal_site.pdf. Acesso em 20 de marco de 2021.

BRASIL. Lei n.0 9.934, de 20 de dezembro de 1996. Lei de Diretrizes e Bases da Educação Nacional. Brasília: MEC, 1996.

BRASIL. Constituição da república federativa do Brasil: promulgada em 5 de outubro de 1988. Disponível em: http://www.planalto.gov.br/ccivil_03/constituicao/constituicao.htm. Acesso em: 18 set. 2020.

CAVALCANTE JÚNIOR, J. A. H; CARNEIRO, I. M. S. P; CAVALCANTE, L. V. S. Alfabetização científica e a formação do profissional cidadão: reflexões do Projeto Pedagógico do Curso Técnico em Agropecuária do IFCE campus Crateús. \# Tear: Revista de Educação, Ciência e Tecnologia, v. 10, n. 1, 2021. Disponível em: https://periodicos.ifrs.edu.br/index.php/tear/article/view/5029. Acesso em: 11 jul. 2021.

CHASSOT, A. Alfabetização científica: uma possibilidade para a inclusão social. Revista Brasileira de Educação, n. 22, p. 89-100, 2003. Disponível em:

https://www.scielo.br/scielo.php?script=sci_arttext\&pid=S1413-24782003000100009. Acesso em: 13 jul. 2020. 
CORTEZ, J.; DEL PINO, J. C. O enfoque cts nos cursos de licenciatura em ciências da natureza. Revista Signos, v. 40, n. 2, 2019. Disponível em:

http://www.meep.univates.br/revistas/index.php/signos/article/view/2425/1564. Acesso em: 10 jul. 2021.

CORTEZ, J.; DEL PINO, J. C. As Diretrizes Curriculares Nacionais para os Cursos de Licenciatura em Ciências da Natureza e o Enfoque CTS. Revista Brasileira de Pesquisa em Educação em Ciências, p. 27-47, 2018. Disponível em:

https://periodicos.ufmg.br/index.php/rbpec/article/view/4600. Acesso em: 10 jul. 2021.

COUTO, C. C. F. A.; NASCIMENTO, W. J.; Percepções sobre o Ensino de Ciências por Investigação a partir de Produções Acadêmicas Brasileiras. Revista Ciência \& Ideias, p. 215-233, v. 11, n. 3, 2020. ISSN: 2176-1477.

DIESEL, A. et al. Contribuições da Língua Portuguesa para uma proposta de Letramento Científico e Tecnológico no contexto escolar. Revista Eletrônica Debates em educação Científica e Tecnológica, v. 6, n. 02, p. 58-70, 2016. Disponível em: http://ojs.ifes.edu.br/index.php/dect/article/view/159. Acesso em: 15 jul. 2020.

GIL, A. C. Como elaborar projetos de pesquisa. 6. ed. São Paulo: Atlas, 2018.

GIL, A.C. Métodos e técnicas de pesquisa social. 6. ed. São Paulo: Atlas, 2008.

KLEIMAN, A. B., "Modelos de Letramento e as Práticas de Alfabetização na Escola", In: Kleiman, A.B. (org.), Os Significados do Letramento - Uma nova perspectiva sobre a prática social da escrita. Campinas: Mercado das Letras, 2005.

MINAYO, M. C. S. Ciência, técnica e arte: o desafio da pesquisa social. IN: MINAYO, M. C. S. (org.). Pesquisa social: teoria, método e criatividade. 34. ed. Petrópolis: Vozes, 2015.

MORAES, R.; GALIAZZI, M. C. Análise Textual Discursiva. 2. ed. Ijuí: Unijuí, 2013.

OLIVEIRA, S. G. S. A alfabetização científica no ensino fundamental: desafios encontrados pelos docentes em escolas municipais de Ilhéus-Bahia; Dissertação (Mestrado) - Universidade Estadual de Santa Cruz. Programa de Pós-Graduação em Educação em Ciências. - Ilhéus, BA: UESC, 2017.

REIS, G. de A.; CAVALCANTE, L. V. S.; OLIVEIRA, E. C. O conceito de Alfabetização Científica e a possibilidade de interações entre cinco competências gerais da Base Nacional Comum Curricular BNCC. Research, Society and Development, 9(8), 2020. DOI: 10.33448/rsd-v9i8.6507.

SANTOS, W. L. P.; MORTIMER, E. F. Uma análise de pressupostos teóricos da abordagem C-T-S (Ciência - Tecnologia - Sociedade) no contexto da educação brasileira. ENSAIO - Pesquisa em Educação em Ciências, v. 2, n. 2, dez., p. 1-23, 2002.

SASSERON, L. H. Ensino de Ciências por Investigação e o Desenvolvimento de Práticas: Uma Mirada para a Base Nacional Comum Curricular. Revista Brasileira de Pesquisa em Educação em Ciências, v. 18, n. 3, p. 1061-1085, set-dez, 2018.

SASSERON, L. H.; CARVALHO, A. M. P. Almejando a alfabetização científica no ensino fundamental: a proposição e a procura de indicadores do processo. Investigações em Ensino de Ciências, Porto Alegre, v. 13, n. 3, p. 333-352, 2008. Disponível em:

http://www.if.ufrgs.br/ienci/artigos/Artigo_ID199/v13_n3_a2008.pdf. Acesso em: 20 jul. 2020. 
SASSERON, L. H.; CARVALHO, A. M. P. de. 2011. Alfabetização científica e tecnológica: uma revisão bibliográfica. Investigações em Ensino de Ciências. V. 16(1): 59-77, 2011.

SOARES, M. Letramento e alfabetização: as muitas facetas. Rev. Bras. Educ. Rio de Janeiro, n. 25, p. 5-17, Apr. 2004. DOI: 10.1590/S1413-24782004000100002.

SCHVINGEL, C; SCHNEIDER, M. C; SCHWERTNER, S. F; JASPER, A. Uma experiência pedagógica em espaços não formais de aprendizagem. Trilhas Pedagógicas, v. 6, n. 6, Ago. 2016, p. 184195.

TEIXEIRA, F. M. Alfabetização científica: questões para reflexão. Ciênc. educ. (Bauru), Bauru, v. 19 , n. 4, p. 795-809, 2013.

Submissão: 22/07/2021

Aceito: 16/10/2021 